\title{
Raymond U. Osarogiagbon: lung cancer is a global challenge that needs our close cooperation!
}

Submitted Sep 14, 2018. Accepted for publication Sep 14, 2018.

doi: $10.21037 /$ tlcr.2018.09.12

View this article at: http://dx.doi.org/10.21037/tlcr.2018.09.12

\section{Editor's note}

Every year, the number of people who die of lung cancer is more than the sum of that of breast, colon, and prostate cancers. Statistically, lung cancer is the second most common cancer that occurs in both male and female population. It is estimated by the American Cancer Society that there will be approximately 234,000 new cases of and 154,000 deaths from lung cancer in 2018 (1). The statistics are alarming and have come to the attention of lung cancer experts from all over the world.

Prof. Raymond U. Osarogiagbon currently serves as Director of the Multidisciplinary Thoracic Oncology Program at the Baptist Cancer Center, Memphis, Tennessee, which is the dominant clinical oncology service provider in the demographically heterogeneous tri-state region of East Arkansas, North Mississippi and West Tennessee, with some of the highest lung cancer incidence rates in the US. Over the years, Prof. Osarogiagbon has been striving to improve population-based systems of care, enhance accuracy of cancer staging and evaluate the biologic drivers of outcome differences in potentially curable lung cancer.

Translational Lung Cancer Research (TLCR) is pleased to invite Prof. Osarogiagbon for the following interview with a focus on several research projects and clinical trials his team is currently working on as well as the interesting and challenging aspects of his research.

\section{Expert introduction}

Raymond U. Osarogiagbon, MBBS, FACP, serves as Director of the Multidisciplinary Thoracic Oncology Program at the Baptist Cancer Center, Memphis, Tennessee, and Director of the Thoracic Oncology Research (ThOR) Group of the Baptist Cancer Center (Figure 1). He is a Research Professor at the University of Memphis School of Public Health, a Research Member of the Vanderbilt Ingram Cancer Center, and a member of the Lung Cancer

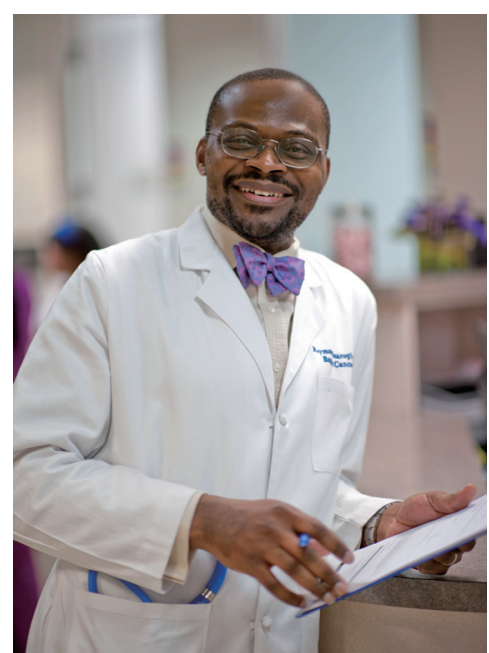

Figure 1 Prof. Raymond U. Osarogiagbon.

Disparities Center of the Harvard School of Public Health. $\mathrm{He}$ is board certified in the Internal Medicine subspecialties of Hematology and Medical Oncology, and a Fellow of the American College of Physicians.

Prof. Osarogiagbon was the Principal Investigator of two major recently-completed regional projects: R01 CA172253-01, a US National Institutes of Health R01funded regional quality improvement project titled 'Dissemination and implementation of a corrective intervention to improve mediastinal lymph node examination in resected lung cancer'; and IH-1304-6147, the Patient Centered Outcomes Research Institute-funded comparative effectiveness study of multidisciplinary v serial care for lung cancer titled 'Building a Multidisciplinary Bridge Across the Quality Chasm in Thoracic Oncology'(ClinicalTrials.gov Identifier: NCT02123797).

Prof. Osarogiagbon is actively involved in a variety of academic societies, including the Alpha Omega Alpha Honor Medical Society, American Society of Clinical Oncology, and the International Association for the Study of Lung Cancer. For the US National Institutes 
of Health (NIH) he is a standing member of the Health Services Organization and Delivery study section, the Cancer Prevention Steering Committee, and leader of the National Cancer Institute's Cancer Screening and Prevention Research Interest Group. He is also a member of the SWOG Board of Governors, serves on the board of The Hope Foundation for Cancer Research and co-chairs SWOG's Early Thoracic Malignancies Sub-committee. In addition, he is the current Chairman of the International Association for the Study of Lung Cancer Membership Committee, and a member of that organization's Staging and Prognostic Factors Committee. In 2018, Dr. Osarogiagbon was elected into the Fleischner Society. He is also an Associate Editor of TLCR.

\section{Interview}

TLCR: Your team has conducted a study called "SILENT" that uses a surgical specimen collection kit to test the impact of improved lymph node examination on the quality of pathologic nodal staging of lung cancer, stage distribution and survival. What is the current status of this study?

Prof. Osarogiagbon: SILENT (Strategies to Improve Lymph node Examination in Non-small cell lung Tumors) at this time is still a proposed institutional cluster randomized trial that we are developing through SWOG and the US National Clinical Trials Network mechanism. Our progress has been somewhat delayed as we have searched for a natural home for this trial. Because it does not involve a specific drug, but rather seeks to evaluate the impact of a lymph node specimen collection device on the quality of surgical care and pathologic nodal staging, it has proven to be a somewhat hard sell through the usual NIH clinical trials funding mechanism. However, with The Hope Foundation for Cancer Research (SWOG's philanthropic fundraising arm) support, we are currently in the fund raising phase to execute this trial for which there is a great deal of interest among lung cancer surgeons, pathologists, medical and radiation oncologists.

TLCR: What are the major barriers to the improvement of the pathologic evaluation of lung cancer resection specimens?

Prof. Osarogiagbon: Our 'chain of responsibility' conceptual model envisions the challenge of pathologic (especially, nodal) staging at 5 key steps: the surgical retrieval of lymph nodes during the operation itself; the accurate labelling (mapping of the anatomic origin) of specimens; the secure transfer of material from the surgical theater to the pathology laboratory; the thorough examination of all provided material; and the accurate reporting of findings within the final pathology report. This conceptual model recognizes the reality that pathologic evaluation of lung resection specimens is a team effort and acknowledges the interdependence of each team member on other team members up and down this chain, for the ultimate success of the entire effort. Like all chains, the chain of responsibility is only as strong as its weakest link, whichever link that proves to be in each individual institution, team or patient's case.

TLCR: Over the past few years, what are the major breakthroughs in the identification of molecular predictors of response to adjuvant therapy and independent molecular prognosticators from gene and protein expression profiles of primary tumors?

Prof. Osarogiagbon: There is a lot of interest in understanding the molecular drivers of outcome differences. Understanding why two patients with the same disease can have such widely different outcomes is an interesting and ongoing challenge. Clearly, a major problem is the horrible difference in quality of care, but that is only one part of the story. My research team has worked for over a decade to scrub through the impact of heterogeneous quality of care, to get through to a large population of patients who have received uniformly high-quality care, in order to study the biologic drivers of outcomes disparity. We are now much closer to being able to do this work, because of the past decade of quality improvement work we have conducted within high lung cancer incidence populations in the Southern US.

Clearly, ongoing clinical trials such as the 'Adjuvant Lung Cancer Enrichment Marker Identification and Sequencing Trials' (ALCHEMIST) basket of trials (including the ALCHEMIST-Screening Trial [A151216]; ALCHEMIST_EGFR Treatment Trial [A081105]; ALCHEMIST-ALK Treatment Trial [E4512]; and ALCHEMIST - Immunotherapy Treatment Trial [ANVIL; EA5142]) will help accelerate knowledge in this direction as we await results showing the impact of adjuvant targeted 
and immune-based therapies on the long-term survival of patients with activating mutations of EGFR who receive adjuvant therapy with effective tyrosine kinase inhibitors (in this case, Erlotinib); ALK mutations treated with Crizotinib; and patients without either of these mutations treated with the immune checkpoint inhibitor Nivolumab (ANVIL). Even more importantly, the collection of biologic specimens embedded in this trial will provide a rich motherlode of knowledge about biologic drivers of outcomes.

Unfortunately, I predict that we will also clearly see the severe adverse impact of existing differences in the quality of surgical resection-within this large trial with patients recruited from a large, diverse, heterogeneous group of institutions within the National Clinical Trials Network and the National Cancer Institute's Community Oncology Research Programs-on survival and the interpretability of molecular differences.

\section{TLCR: Would you introduce us to a recent NIH-funded research project that you are involved in?}

Prof. Osarogiagbon: We just recently completed a 5-year dissemination and implementation R01 grant in which we tested the impact of deploying a surgical specimen collection kit for use in lung cancer surgery across 12 institutions within four contiguous Dartmouth Hospital Referral Regions in the states of Mississippi, Arkansas and Tennessee, states with the $2^{\text {nd }}, 3^{\text {rd }}$ and $4^{\text {th }}$ - highest lung cancer incidence and mortality rates in the US. Subsequently, we were fortunately to be successful in our competitive renewal R01 grant (2R01CA172253-06) in which we now propose to layer on an intervention designed to improve the gross dissection of lung resection specimens in order to reduce the inadvertent loss of intrapulmonary lymph node materials during examination in the pathology laboratory. This project involves all pathology groups within 12 hospitals across 7 different healthcare systems within the same 4 Dartmouth Hospital Referral Regions which provides our catchment area. The grant is a 5-year R01 which began in August 2018, with work projected to continue until mid-August 2023, it has a budget of approximately $\$ 2.5$ million.

TLCR: What do you regard as the most challenging aspects of research? How do you overcome these challenges?

Prof. Osarogiagbon: My greatest challenge is time management. Time is our most precious resource over which we have the least control. We cannot know how much time we have left in our lives. As the British explorer, Cecil Rhodes, is reported to have said at his deathbed 'so much to do'... so little time'. I don't know that one can overcome the challenge of time, but I am still learning to prioritize how I use my time, while striving for balance between divergent and often conflicting interests and obligations, such as work versus home responsibilities; clinical versus administrative versus research versus community service etc. I have been very fortunate that my wife has supported me throughout my career, allowing me to steal time, especially early on in my career, from my domestic responsibilities. She kept watch over the raising of our children and other family obligations while I 'had my head in the clouds', as they tell me at home. Work-life balance is vital. Unfortunately, I think I've failed to achieve that, but I'm trying...

\section{TLCR: What leads you to the path of thoracic oncology research? What has been driving you to move forward and make progress in your research field?}

Prof. Osarogiagbon: The holocaust that is lung cancer. The 1.7 million individuals diagnosed, 1.5 million dead every year worldwide; 230,000 diagnosed, 160,000 dead in the US annually; 17\% aggregate 5-year survival (in the US, but much worse elsewhere). These are statistics that boggle my mind, and make me wake up every morning with a sense of urgency and purpose.

\section{TLCR: As the Associate Editor of TLCR, do you bave any words for our readers/peers in your field?}

Prof. Osarogiagbon: Lung cancer is a global challenge which will overwhelm us unless we come together as a global community to learn from each other so we can share our best ideas and keenest insights. We need to implement the best practices within our individual circles of influence and disseminate discoveries quickly, efficiently, so lives can be saved. Journals like TLCR provide a platform for us to come together and learn from each other.

\section{Acknowledgements}

We would like to express our sincerest gratitude to Prof. Raymond U. Osarogiagbon for sharing his insights and opinions with us. 


\section{References}

1. American Cancer Society [Internet]. The United States: American Cancer Society, 2018 [cited 2018 Sep 13].

Cite this article as: $\mathrm{Li} \mathrm{B}$. Raymond U. Osarogiagbon: lung cancer is a global challenge that needs our close cooperation! Transl Lung Cancer Res 2018;7(Suppl 4):S393-S396. doi: 10.21037/tlcr.2018.09.12
Available online: https://www.cancer.org/cancer/nonsmall-cell-lung-cancer/about/key-statistics.html

(Science Editor: Brad Li, TLCR, editor@tlcr.org) 